\title{
Peranan Dakwah Kismis Purwakarta secara Online dalam Menyiarkan Islam
}

\author{
Syifa Fauzi Karimah* \\ Prodi Komunikasi Penyiaran Islam, Fakultas Dakwah, Universitas Islam \\ Bandung, Indonesia. \\ *uzikasyifa@gmail.com
}

\begin{abstract}
The development of the times brought preaching to the online media. Dakwah KISMIS (Islamic Studies Every Thursday) in Purwakarta carries out its Islamic broadcasts using various social media with a research focus on the role of online preaching of KISMIS in Purwakarta in broadcasting its Islamic messages. This research uses descriptive qualitative methods and is analytical in nature. Where the research analyzes the results of interviews with respondents who take part in KISMIS through online media from various social media to spread Islamic messages which contain faith, sharia and morals. In the results of this study, it is concluded that the role of the message of tauhid KISMIS does not play a role because there are several differences of opinion regarding faith in qadha and qadar regarding unhabbed prayer. It is the same as the role of the Shari'a message which is considered to have less role, because there are many differences of opinion and views regarding prayer and the intention to fast. Whereas in the role of messages regarding morals it is also considered to have less role, because there are different views on the morals of children to parents of different religions who have died and manners to tormented animals. So it can be said that the role of online KISMIS is insufficient in broadcasting Islam in Purwakarta due to the lack of meaning of the da'wah messages conveyed to respondents in the study so that it gives different views and understandings with some respondents who are followers of KISMIS through online media.
\end{abstract}

\section{Keywords: Islamic Da'wah, Online Media, Role}

Abstrak. Berkembangnya zaman membawa dakwah masuk dalam media online. dakwah KISMIS (Kajian Islam Setiap Kamis) di Purwakarta melakukan syiar Islamnya dengan menggunakan berbagai media sosial. Penelitian berfokus pada peranan dakwah KISMIS di Purwakarta secara Online dalam menyiarkan pesanpesan Islamnya. Penelitian ini menggunakan metode kualitatif deskriptif dan bersifat analisis. Dimana penelitian menganalisis hasil dari wawancara pada responden yang mengikuti KISMIS melalui media online dari berbagai media sosial untuk menyiarakan pesan Islam yang berisikan akidah, syariat dan akhlak. Dalam hasil penelitian ini mendapatkan kesimpulan mengenai peranan pesan tauhid KISMIS kurang berperan karena ada beberapa perbedaan pendapat mengenai iman kepada qadha dan qadar perihal doa yang belum terijabah. Sama dengan peranan pesan syariat yang dinilai kurang berperan, karena ada banyaknya perbedaan pendapat dan pandangan mengenai shalat dan niat berpuasa. Sedangkan dalam peranan pesan mengenai akhlak juga dinilai kurang berperan, karena ada perbedaan pandangan mengenai akhlak anak kepada orang tua berbeda agama yang sudah meninggal dan adab kepada hewan yang terdzalimi. Sehingga dapat dikatakan kurang berperannya KISMIS secara online dalam menyiarkan Islam di Purwakarta dikarenakan adanya beberapa makna pesan dakwah yang kurang tersampaikan kepada responden dalam kajian sehingga memberikan perbedaan pandangan dan pemahaman dengan beberapa responden yang menjadi pengikut KISMIS melalui media online.

Kata Kunci: Dakwah Islam, Media Online, Peranan 


\section{A. Pendahuluan}

Zaman yang sudah semakin maju membawa media menjadi semakin berkembang. KISMIS (Kajian Islam Setiap Kamis) merupakan salah satu kegiatan dakwah yang bertempat di Purwakarta yang mengikuti zaman dalam dakwahnya. Dengan menggunakan media online dari berbagai platfrom media sosial untuk menyiaran pesan-pesan dakwahnya.

Luasnya jangkauan media sosial membuat keheterogenan pengikut KISMIS dari berbagai media sosial yang digunakannya. Hal tersebut memberikan nilai tambah dengan tidak terbatasnya pendengar namun memberikan kekurangan pada KISMIS untuk memperhatikan peranan dakwahnya dalam media online agar tersampaikannya isi pesan kepada pengikutnya sehingga adanya kesamaan pemahaman dari apa yang disyiarkan dengan kepahaman dan implementasi para pengikut KISMIS. Hal tersebut memberikan ketertarikan peneliti dalam peranan dakwah KISMIS di Purwakarta dalam menyiarkan pesan-pesan dakwahnya melalui media online.

\section{Metode Penelitian}

Jenis penelitian ini adalah kualitatif dengan metode kualitatif deskriptif yang bersifat analitik. digunakannya data yang bersifat deskriptif analitik dengan menggambarkan hasil penelitian namun tidak membuat kesimpulan yang luas . Dari hasil dari proses pengolahan data pada penelitian ini bertujuan untuk memberikan gambaran dari peranan dakwah KISMIS melalui media online dengan mengambil kesimpulan yang tidak begitu luas namun dengan data yang valid.

Subjek dalam penelitian ini adalah peranan dakwah Islam KISMIS yang dilakukan di berbagai media sosial. KISMIS yang memiliki pengikut kurang lebih 1.366 di Istagram , $1.55 \mathrm{k}$ subscriber youtube , 3.953 pengikut di Facebook, dan ratusan partisipan di WhatsAppsGroup KISMIS . Dari banyaknya pengikut KISMIS di media online peneliti mengambil tujuh responden dari pengikut KISMIS di berbagai media sosial yang digunakan dengan mewawancarai responden terkait kepahaman dari isi kajian KISMIS. Peneliti mengambil jumlah sampling berdasarkan sampling aksidental yang meskipun sedikit namun informasi yang didaptakan diyakini dapat menjadi sumber data.

\section{B. Landasan Teori}

\section{Peranan Dakwah Islam}

Peran merupakan suatu perangkat tingkah laku yang diharapkan untuk dimiliki oleh orang yang berkedudukan dimasyarakat, sebagaimana peranan juga merupakan perilaku yang diatur dan diharapkan dari seseorang dalam posisi tertentu. Sedangakan kata dakwah yang diambil dari bahasa arab دعوة dari kata (da'a) يدعو ( yad'u), yang artinya panggilan, ajakan, dan seruan. Dakwah juga dapat di artikan mengajak kepada kebaikan, Mendorong manusia agar berbuat kebajikan dan petunjuk, menyuruh mereka berbuat ma'ruf dan melarang mereka dari perbuatan mungkar, agar mereka mendapatkan kebahagiaan di dunia dan akhirat . Untuk terlaksananya dakwah Islam, dibutuhkan unsur-unaur dakwah seperti

1. $D a ' i$ : Sumber atau yang disebut juga sebagai pengirim pesan baik secara verbal ataupun non verbal, Sehingga dapat dikatakan seorang $d a^{\prime} i$ bukan hanya harus mengetahui keilmuan tertentu, namun juga menguasai nya dan mempraktikannya sehingga dapat dijadikan contoh. . Pengirim pesan dalam Kajian Islam Setiap Kamis terdiri dari 3 ustadz yang pengisinya bergiliran setiap seminggu sekali.

2. Materi/ pesan: materi atau pesan dakwah yang merupakan isi yang di sampaikan oleh da'i. Pesan dakwah KISMIS berisikan akidah, syariat dan akhlak dan tema yang disampaikan diserahkan kepada pemateri.

3. Media: media merupakan alat atau jembatan untuk penyampaian pesan dari da'i kepada mad'u. Media dakwah yang KISMIS gunakan adalah media online dengan menggunakan berbagai media sosial.

4. Metode: metode merupakan cara penyampaian untuk melaksanakan suatu pekerjaan agar tercapai sesuai dengan yang dikehendaki . Dalam dakwah digunakannya metode dakwah bil hal, mauidzah hasanah dan mujadalah. 
5. Mad'u: Mad'u atau objek dakwah berupa perorangan atau kelompok yang dituju oleh dai dalam penyampaian pesannya. Mad'u dalam kajian KISMIS yang bersifat heterogen, karena berbagai macam pengikut melalui media online yang berbeda-beda juga.

\section{Media Online}

Dalam pelaksanaan dakwah, KISMIS menggunakan media online untuk menyiarkan pesanpesan Islamya. Dengan menggunakan berbagai macam platfrom media sosial seperti Instagram, Facebook, WhatsAppsGroup dan Youtube berupa vidio atau lifestreaming.

Luasnya media untuk berdakwah menjadi peluang bagi para pendakwah dalam penyampaian pesan. Sehingga tak hanya memudahkan para pendakwah, namun luasnya media dakwah juga mempermudah para penerima dakwah atau mad'u untuk menerima informasi atau menerima pesan dakwah.

Melihat bagaima peranan dakwah KISMIS dalam menyiarkan pesan-pesan Islamnya melalui berbagai media sosial terlihat dari kepahaman dan kesamaan pandangan mad'u dari pesan-pesan yang sudah disampaikan oleh para da'i. Dari hal ini digunakannya teori komunikasi persuasif, yang ditujukan untuk menginnformasikan dan meyakinkan orang lain agar berfikir atau bertindak sesuai dengan pesan yang disampai oleh pengirim pesannya (da'i).

\section{Hasil Penelitian dan Pembahasan}

\section{Peranan Dakwah Dalam Menyiarkan Akidah}

Bersasarkan hasil wawancara yang dilakukan peneliti mengenai akidah dengan pengambilan pertanyaan dari isi kajian KISMIS mengenai iman kepada Allah dengan dengan penjelasan mengenai syirik, iman kepada Rasulullah iman dengan pertanyaan berupa pemahaman responden mengenai iman kepada Rasulullah, iman kepada hari akhir dengan contoh pertanyaan takut melakukan dosa karena takut akan balasannya, dan iman kepada qadha dan qadar dengan contoh pertanyaan terkait doa yang tertolak dan terhalang. Adanya perbedaan pemahaman terkait perntanyaan mengenai iman kepada qadha dan qadar terlihat dari jawaban responden yang berbeda dengan apa yang sudah dijelaskan dalam dakwah KISMIS

\section{Peranan Dakwah Dalam Menyiarkan Syariat}

Bersasarkan hasil wawancara yang dilakukan peneliti mengenai syariat dengan pengambilan pertanyaan dari isi kajian KISMIS mengenai ubudiyah dan muamalah. peneliti pengambilan pertanyaan terkait ubudiah dengan contoh terkait sholat jumat, shalat orang yang keputihan, aurat sharat, kedatangan najis suci haid dan niat berpuasa, dan mengenai muamalah dengan mengambil contoh hutang mayat. Adanya perbedaan pemahaman terkait ubudiah mengenai hukum shalat, niat berpuasa dan suci haid terlihat dari jawaban responden yang berbeda dengan apa yang sudah dijelaskan dalam dakwah KISMIS

\section{Peranan Dakwah Dalam Menyiarkan Akhlak}

Bersasarkan hasil wawancara yang dilakukan peneliti mengenai akhlak dengan mengambil pertanyaan dari isi kajian KISMIS mengenai akhlak kepada Allah dengan pertanyaan mengenai syukur, akhlak kepada Rasulullah dengan pertanyaan berupa pemahaman mengenai akhklak kepada Rasulullah, akhlak kepada sesama manusia dengan pertanyaan akhlak anak kepada orangtua yang sudan meninggal namun berbeda agama dan akhlak kepada sesama makhluk dengan perntanyaan adab kepada hewan. Adanya perbedaan pemahaman terkait pertanyaan mengenai akhlak anak kepada orang tua berbeda agama dan sudah meninggal terlihat dari jawaban responden yang berbeda dengan apa yang sudah dijelaskan dalam dakwah KISMIS 


\section{Kesimpulan}

Melihat bagaimana perananan dakwah KISMIS dalam menyiarkan pesan-pesan akhidah, syariat dan akhlak berdasarka hasil wawancara yang dianalisis dinilai kurang berperan, karena adanya perbedaan pandangan dan pemahaman dalam akidah mengenai iman kepada qadha dan qadhar melalui konsep doa yang belum terijabah atau tertolak dikarenakan responden memberikan pendapat dengan meniadakan pengertian doa yang tertolak dan memberikan pandangan bahwa hal tersebut hanya perihal waktu atau kekhusyukan dalam berdoanya saja.

Mengenai peranan dakwah KIMSMIS dalam menyiarkan syariat dinilai kurang berperan karena dalam pertanyaan terkait shalat yang sedang keputihan karena beberapa responden memiliki pandangan bahwa tidak apa-apa sholatnya orang yang sedang keputihan atau ada juga yang menjawab dengan ketidak tahuan hukum dari keputihan, kemudia contoh dalam aurat shalat wanita reponden berbeda dengan dalam kajian mengenai terlihatnya kaki saat sedang sholat dikarenakan tersingkap mukena yang oleh angin, ada beberapa responden yang berpendapat tidak apa-apa dan bisa melanjutkan sholat jika langsung ditutup kembali. Perbedaan juga dalam pembahasan mengenai shalat Jumat seseorang yang bermain HP saat sedang khutbah Jumat karena ada beberapa responden yang berpendapat tidak apa-apa jika mendesak dan hal tersebut dapat mengurangi pahala Jumatannya dan dari beberapa responden berpendapat tidak apa-apa shalat Jumatnya laki-laki di pabrik yang jauh dari rumah tanpa menjelaskan harus 40 orang warga setempat. Selain itu perbedaan pandangan dan pendapat juga dalam bahasan niat berpuasa karena dari beberapa responden beranggapan jika niat berpuasa hanya cukup dilafalkan saja tidak di tekankan dalam hati

Mengenai peranan dakwah KIMSMIS dalam menyiarkan akhlak dinilai kurang berperan, karena adanya perbedaan paham dalam pertanyaan terkait akhlak kepada sesama manusia dengan contoh akhak anak yang berbeda agama kepada orang tuanya yang sudah meninggal. Dari beberapa responden berpendapat seorang anak terap mendoakan orang tua yang berbeda agama meskipun berbeda agama.

\section{Daftar Pustaka}

[1] Abdullah, Muhammad Qadaruddin. 2019. Pengantar Ilmu Dakwah. Pasuruan: CV. Penerbit Qiara.

[2] Aziz, Moch Ali. 1993. Ilmu Dakwah. skripsi, surabaya: Fakultas Dakwah IAIN Sunan Ampel.

[3] Barata, atep adya. 2017. dasar-dasar pelayanan prima. Jakarta: PT. Elex Media Komutinndo.

[4] Muhammad Munir, Wahyu Ilahi. 2006. Manajemen Dakwah . Jakarta: Kencana.

[5] Rivai, Veithzal. 2009. Education Management, analisis teori dan praktik. Jakarta: PT. Raja Grafindo.

[6] Sofyan. 2019. Tafsir Islam Atas Adata Gorontalo. Malang: PT. Citra Intrans Selaras.

[7] Syamsuddin. 2016. Pengantar Ilmu Sosiologi Dakwah. Jakarta: Kencana.

[8] Wahid, Abdul. 2019. Gagasan Dakwah; Pendekatan Komunikasi Antar Budaya. Jakarta: Prenadamedia Group.

[9] https://www.instagram.com/kismis_kajianislamsetiapkamis/?hl=en diakses hari Selasa, 19 Januari 2021 pukul 14.55

[10] https://www.youtube.com/channel/UCDId0FR_wdmrB988UiKsnuw/videos diakses hari Selasa, 19 Januari 2021 pukul 14.55

[11] https://www.facebook.com/kismis.kismis.9822 diakses hari Selasa, 19 Januari 2021 pukul 14.55

[12] chat.whatsapp.com/D0iWpwCy7BLAxHSraTAwKA diakses hari Selasa, 19 Januari 2021 pukul 14.55 